\title{
Study on fire risk assessment of offshore platforms
}

\author{
Tao Chen ${ }^{1, *}$, Lin Wang ${ }^{2}$ \\ ${ }^{1}$ School of Civil Engineering and Architecture, Jiangsu University of Science and Technology, Zhenjiang, Jiangsu, China \\ ${ }^{2}$ School of Civil Engineering and Architecture, Jiangsu University of Science and Technology, Zhenjiang, Jiangsu, China
}

\begin{abstract}
As a modern infrastructure for offshore oil and gas resources development, offshore platforms have many advantages, such as high efficiency, concentration, flexibility, and repeatability. At the same time, its upper module environment is bad, the equipment is numerous, has the very big risk. In case of fire and explosion and other accidents, it is difficult to get timely rescue. Therefore, fire risk assessment for offshore platform is very necessary. This paper focuses on the research results in the field of fire risk assessment of offshore platforms at home and abroad, points out the shortcomings of current research, and provides reference for risk reduction and effective prevention of offshore platform operations.
\end{abstract}

\section{Preface}

Energy and environmental protection are two prominent problems in the world today, which restrict the development of economy. In order to meet the economic development, the whole world is advocating energy conservation, energy search and adjust the energy structure.

Natural gas has a high calorific value, the combustion products are basically carbon dioxide and water, and less pollution to the environment, so it has a superior application prospect.

The sea contains vast resources of oil and gas. At present, many countries in the world will focus on the exploitation and application of natural gas in the offshore, so the construction and use of a large number of offshore platforms has become inevitable.

Offshore platform is a kind of offshore oil and gas exploitation platform, the operating environment is harsh, there are a lot of flammable and explosive substances, a little careless will cause a serious accident ${ }^{[1]}$. There have been a lot of researches on fire risk assessment for ground buildings, but the fire risk assessment for offshore platform is still very few. In this paper, the fire risk assessment of offshore platforms based on building fire risk assessment methods is comprehensively reviewed.

\section{Fire types and characteristics of offshore platforms}

Fires on offshore platforms mainly include the following types:

Spray fire: the medium processed on the platform is mainly crude oil or natural gas, which is extremely combustible. Once it encounters the ignition source after leakage, it will be ignited and cause a fire, just like the flame ejector, forming a spray fire. ${ }^{[2]}$
Flash fire: Flash fire is a non-explosive vapor cloud 6 combustion that occurs when combustible gases or vapors escape into the air and mix with it after being ignited.

The main hazards are thermal radiation and direct flame burning. ${ }^{[3]}$

Pool fire: A pool fire is when a flammable liquid leaks onto the ground or water. This kind of fire damage ability is not easy to extinguish, will make the whole platform structure in the fire in an instant.

Steam cloud explosion: An explosion caused by corrosion failure of a natural gas pipeline or delayed ignition caused by material leakage during mechanical failure. It mainly relies on the blast wave to cause damage to people and buildings. ${ }^{[3]}$

Compared with ordinary building fires, it is very difficult to rescue offshore platforms. At the same time, because crude oil and natural gas leakage will cause serious Marine environmental pollution, the risk assessment of relevant facilities of offshore platforms is of great significance.

\section{General steps for fire risk assessment on offshore platforms}

Offshore platform is a large complex system, which can be divided into several sub-modules for analysis in order to facilitate evaluation. This sub-module can be an area, such as the main machine room, or a separate system, such as the fire protection system. Each type of module can be analyzed separately.

The main steps of fire risk assessment for offshore platforms can be summarized as follows:

(1) Clarify the system and related problems according to the design scheme of the offshore platform, the engineering stage it is in, the structural composition, and the requirements for the confidence of the analysis results;

\footnotetext{
"Corresponding author:835375876@qq.com
} 
(2) find out all possible dangers, but it should be understood that there is no one way to ensure thorough hazard identification;

(3) Cause and consequence analysis;

(4) Risk estimation of the system.

\section{Identification of fire and explosion hazard sources for offshore platforms}

The initial step of fire risk assessment is the identification of fire hazard sources. Danger sources can usually be divided into two categories.

Accident is the accidental release of energy. Excessive energy acting on the human body or structure or dangerous substances interfering with the exchange of energy between the human body and the outside world are the direct causes of personal injury or property loss. Energy or hazardous substances play a very important role in the cause of accidents, so we call them the first type of hazard sources. They include combustibles, fire smoke and toxic and harmful gas components produced by combustion.

The second type of hazard source is a variety of unsafe factors leading to the failure or destruction of the constraining and limiting energy shielding measures. The second type of hazard sources include human, material, environmental problems in three aspects.

Human error refers to human error, which may directly lead to the accidental release of energy or dangerous substances and thus cause an accident.

Material can be summarized as a failure of material, which may lead to the destruction of energy or hazardous material restraint measures. For example, pipeline rupture leads to the leakage of toxic and harmful substances; Wire insulation damage leads to leakage; Failure of the cooling system causes fire and so on.

Environmental factors refer to physical factors such as temperature, lighting, humidity, ventilation and ventilation. A bad physical environment can cause malfunction or human error. For example, the damp environment causes metal corrosion and thus reduces the strength of the container; Strong noise will disturb people's emotions and lead to mistakes; Poor lighting can lead to slow evacuation and so on.

Hazard identification is a research process of identifying and classifying hazard sources based on factors such as accident cause, location, frequency, consequence and operation type.

The main purpose of hazard identification is to enable relevant technical personnel to find the potential danger of equipment as soon as possible, so as to take corresponding measures to prevent.

Fire hazard identification and fire scene setting are closely linked together. A fire scenario is a description of a particular fire from ignition to the peak of fire growth and the damage caused by the fire.

Through the establishment of fire scene, the characteristics of fire development are analyzed, and the distribution of fire hazard sources in space and time is given in combination with statistical data.

A variety of factors are usually taken into account when establishing a fire scenario, including: the situation before the fire, the ignition source, the initial combustible, the fuel that can be ignited, the likelihood of spread, the target location, the status of the user, and statistics.

For quantitative analysis, some parameters are needed to set fire, such as fire load density, fire growth rate, fire risk, fire heat release rate and other fire-related quantities.

The workflow of hazard identification is as follows.

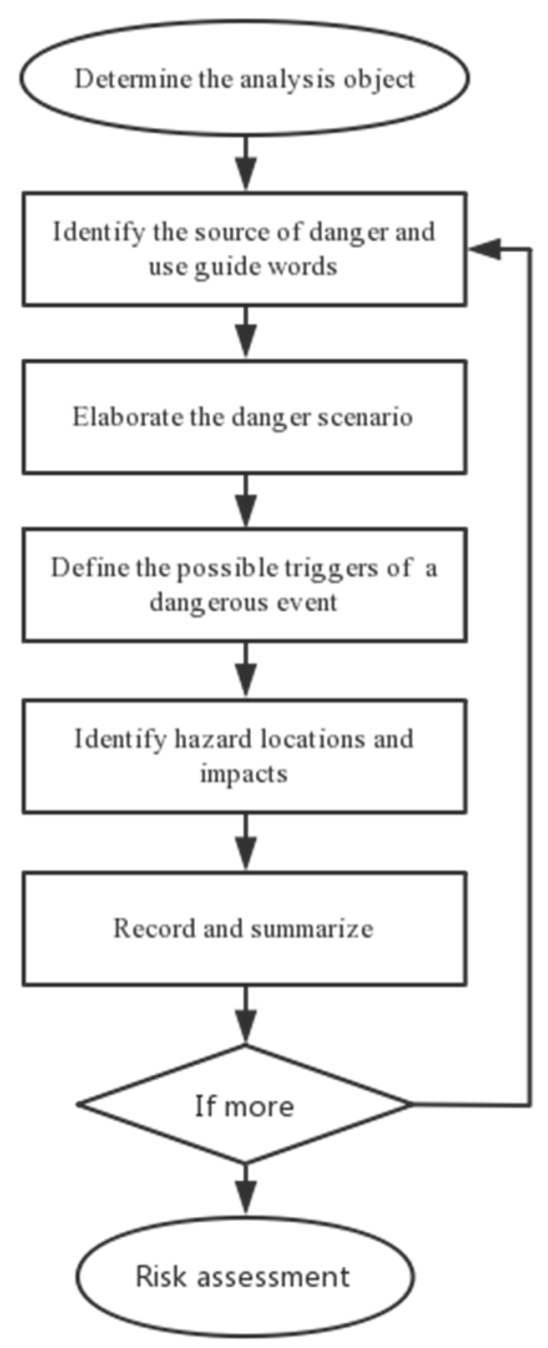

Figure 1 Workflow of hazard identification

The main hazard sources of offshore platforms are high pressure production separation meters, low pressure production metering separators, natural gas coolers and natural gas filters.

The reasons are often complex, such as bolt loosening, equipment corrosion, aging, accidental impact, personnel operating error, open fire environment and so on.

\section{Fire risk analysis for offshore platforms}

There are many methods of fire risk assessment, which can be divided into qualitative analysis, semi-quantitative analysis and quantitative analysis. 
Qualitative analysis is mainly used to identify the most dangerous fire events, but it is difficult to give a fire hazard rating.

Semi-quantitative methods can be used to determine the relative risk of possible fires, as well as to assess the frequency and consequences of fires.

Quantitative analysis is an accurate method of fire risk assessment.

For Quantitative analysis, the calculated risk value can be directly compared with the risk tolerance by considering the probability and result of building fire accident comprehensively.

It is also possible to compare different buildings or different areas of the same building. It has become the most attractive and fastest developing fire risk assessment method.

\subsection{Dow Chemical Company Fire and Explosion Index Evaluation Method}

Dow Chemical Company Fire Explosion Index (DHI) is a fire accident evaluation method for the industrial scope.

Based on the potential risk of fire and explosion of materials in the process, the fire and explosion index can be obtained by combining the factors such as process and material quantity to evaluate the safety of production.

Its quantitative basis is mainly the potential energy of the substance, the current safety measures and the relevant statistical data in the past.

The following is a list of information to be prepared before conducting the Dow Chemical Fire and Explosion Index evaluation:

Table 1. List of information in advance of fire explosion index evaluation method

\begin{tabular}{|c|c|}
\hline The serial number & name \\
\hline 1 & $\begin{array}{l}\text { The design of a plant or } \\
\text { plant }\end{array}$ \\
\hline 2 & $\begin{array}{l}\text { Fire and explosion index } \\
\text { calculation table }\end{array}$ \\
\hline 3 & $\begin{array}{c}\text { Safety measures } \\
\text { compensation coefficient } \\
\text { table } \\
\end{array}$ \\
\hline 4 & $\begin{array}{l}\text { Material coefficient } \\
\text { determination table }\end{array}$ \\
\hline 5 & $\begin{array}{l}\text { Fire explosion index risk } \\
\text { classification table }\end{array}$ \\
\hline 6 & $\begin{array}{l}\text { Summary of process unit } \\
\text { risk analysis }\end{array}$ \\
\hline 7 & $\begin{array}{c}\text { Summary of plant risk } \\
\text { analysis }\end{array}$ \\
\hline 8 & $\begin{array}{c}\text { Data on replacement costs of } \\
\text { the equipment }\end{array}$ \\
\hline
\end{tabular}

The process of Dow Chemical Fire and Explosion Index Evaluation Method is as follows:

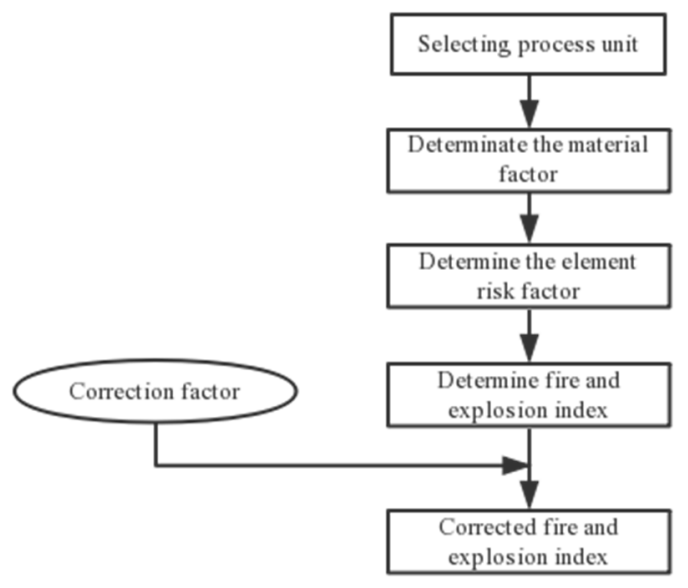

Figure 2 Workflow of DOW

\subsection{Probabilistic risk assessment}

The probabilistic risk assessment method is a safety assessment method based on the accident probability of the basic cause factors of the accident and the probability analysis method in mathematical statistics to obtain the correlation degree (or importance degree) of the basic cause factors of the accident or the accident probability of the whole system. ${ }^{[5,6]}$

The probabilistic risk assessment method is based on a large number of experimental data and accident statistical analysis, so the reliability of the evaluation results is high. Because the accident probability of the system can be given directly, it is convenient to compare the possibility of each system.

For the same system, probabilistic analysis can also get the probability of different accidents.

However, probabilistic analysis requires very accurate and large amounts of data, especially the probability of the occurrence of the accident of the basic cause factors, which is very troublesome for the more complex system.

The most commonly used method is event tree analysis, which starts from the initial state of an event and uses logical thinking to analyze it step by step.

$\mathrm{Up}$ to the end, each situation is either a failure or a success.

Event tree was originally used for reliability analysis. It is one of the systems methods to represent system reliability in terms of component reliability.

Event tree analysis can be briefly summarized as the following four steps :

(1) determine the system and its constituent factors, define the object and scope, and find out the constituent elements of the system;

(2) analyze the causal relationship of each factor and the two states of success and failure;

(3) Starting from the initial state, the event tree is compiled according to the order of system components;

(4) The probability of success and failure of each node is marked and calculated.

Probability analysis also includes fault tree analysis, 
Markov model analysis, fuzzy matrix method, logical tree analysis and so on.

\section{3 mathematical model method}

Mathematical modeling is an approach to typical scenarios. Experts and scholars on the basis of a large number of accident investigation, the specific fire site mathematical modeling, and then obtain a method of accident probability. ${ }^{[7]}$

The establishment of mathematical model needs a lot of data. Therefore, mathematical modeling can only be used when the amount of data used for fire risk assessment is sufficient.

For offshore platforms, system risks are caused by system uncertainties, so how to consider the uncertainties in the system risk assessment has become the key.

The traditional method of probability theory is based on the known premise of the probability of the basic event. When the probability of the basic event cannot be known for various reasons in the process of analysis, this method is difficult to use.

At this time, the probability of fuzzy set can be introduced with the help of expert judgment, which makes the risk assessment of offshore platform possible.

There are two kinds of uncertainties in fire risk assessment of offshore platforms, one is knowledge uncertainty, the other is random uncertainty.

The former can be reduced by supplementing basic information, such as plume coefficients; The latter can be described by probability distributions of population density, wind direction, temperature, fire growth rate, etc.

\section{Risk estimation of the system}

Fire and explosion are major hazards to offshore oil and gas production facilities, and accidents can lead to devastating damage to offshore production facilities, potentially causing serious human casualties and economic losses.

The purpose of cause analysis is to estimate each possible cause and the probability of its occurrence. Consequences analysis is to find out the development course of a trigger event leading to a serious accident.

The overall risk assessment of the system will be carried out by combining the results of cause and effect analysis. Generally speaking, the probability description of the system risk loss will be established.

Sensitivity analysis should be carried out for important uncertain factors.

The consequences of the event can be divided into economic loss, casualties, environmental damage, etc. Some can be measured by quantitative indicators, while others can only be described qualitatively, such as the impact of the accident on the public.

\section{7 conclusion}

Fire and explosion are major hazards to offshore oil and gas production facilities, and accidents can lead to devastating damage to offshore production facilities, potentially causing serious human casualties and economic losses.

Therefore identify offshore assignment in the potential risk and hazard factors of effective control and reduce the production process is the harm to the health, safety and environment and influence of the important link, is to realize the safety supervision and management standardization, reduce the number of hidden dangers and accidents, protect the safety of staff health and the national property safety of the important work.

Different fire risk assessment projects have different fire risk assessment pertinence.

Oil and gas belong to flammable and explosive media. Safety should always be placed in a very important position in the design of offshore platforms.

Different fire risk assessment methods based on different fire scenarios can effectively reduce risks, improve production quality, and reduce personnel and property losses.

\section{References}

1. Mao Weizhi, Chen Hao, Zhu Jiaolin.Fire and explosion simulation analysis of oil and gas treatment equipment leakage on offshore platform: The 15th China Offshore Engineering Symposium, Taiyuan, Shanxi, China, 2011[C].

2. Cai Tao, Liu Peilin, Huo Yili, et al.Research on Fire and Explosion Hazard Identification and Evaluation of Offshore Platform: The 13th Session of the China Association for Science and Technology Annual Meeting - Ocean Engineering Equipment Development Forum, Tianjin, China, 2011[C].

3. Liu Maoyu, Su Lin, Li Xueliang, Bo Wenguang, Shi Li Chen.Analysis of the consequences of flash fire disaster [J]. Journal of Safety and Environment, 2001(04):28-31.

4. Wang Zongze, Tian Chaolun, She Nan, et al.Model analysis of vapor cloud explosion occurring through pipeline [J]. China Science and Technology Information, 2017(Z1):95-96.

5. Zheng Yanqiong, Wang Zhongbo, Wang Bing.Research on fire safety evaluation method [J]. Journal of Armed Police College, 2007(02):42-47.

6. Yan Chengfei. Study on coal mine fire safety evaluation method and software development [J]. Modern Mining, 2019,35(03):166-168.

7. He Jie. Leakage Risk Assessment of LNG Carrier Based on Offshore Platform Collision Accident [D].Jiangsu University of Science and Technology, 2013. 